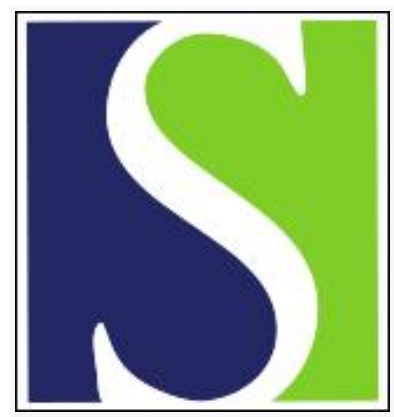

Scand J Work Environ Health 2019;45(5):514-519

https://doi.org/10.5271/sjweh.3828

Published online: 09 May 2019, Issue date: 01 Sep 2019

Health and prolonging working lives: an advisory report of the Health Council of The Netherlands

by van der Mark-Reeuwijk KG, Weggemans RM, Bültmann U, Burdorf A, Deeg DJH, Geuskens GA, Henkens KCJIM, Kant I, de Lange A, Lindeboom M, van Rhenen W, van der Beek AJ

The Health Council of The Netherlands advised the government to focus on interventions to support workers in prolonging their working lives as well as the improvement of implementation of these interventions. Considering the large diversity in health at higher age and between low- and high-educated people, it was further recommended to explore whether flexible pensions schemes better suit this diversity.

Affiliation: Kerstin $\mathrm{G}$ van der Mark-Reeuwijk, Health Council of The Netherlands, PO Box. 16052, NL-2500 BB The Hague, The Netherlands. [E-mail: kvandermark@gr.nl]

Refers to the following texts of the Journal: 2014;40(5):473-482 2013;39(3):233-240 2013;39(2):134-143 2013;39(1):66-75

The following articles refer to this text: 2021;47(1):5-14; 2021;47(3):224-232; 2022;48(4):312-321

Key terms: chronic disease; disability benefit; functioning; health; mental health; need for recovery; older worker; retirement; self-perceived health; sickness absence; sickness absence; The Netherlands; unemployment; work ability; working life

This article in PubMed: www.ncbi.nlm.nih.gov/pubmed/31069395

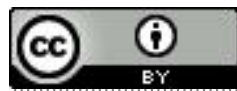




\title{
Health and prolonging working lives: an advisory report of the Health Council of The Netherlands
}

\author{
by Kerstin G van der Mark-Reeuwijk, PhD, ${ }^{1}$ Rianne M Weggemans, PhD, ${ }^{1}$ Ute Bültmann, PhD, ${ }^{2}$ Alex Burdorf, PhD, ${ }^{3}$ Dorly JH \\ Deeg, PhD, ${ }^{4}$ Goedele A Geuskens, PhD, ${ }^{5}$ Kène CJIM Henkens, PhD, ${ }^{6,7,8}$ /Jmert Kant, PhD, ${ }^{9}$ Annet de Lange, PhD, 10,11 \\ Maarten Lindeboom, PhD, ${ }^{12}$ Willem van Rhenen, MD, PhD, 13, 14 Allard J van der Beek, PhD ${ }^{15}$
}

\begin{abstract}
van der Mark-Reeuwijk KG, Weggemans RM, Bültmann U, Burdorf A, Deeg DJH, Geuskens GA, Henkens KCJIM, Kant I, de Lange A, Lindeboom M, van Rhenen W, van der Beek AJ. Health and prolonging working lives: an advisory report of the Health Council of The Netherlands. Scand J Work Environ Health. 2019;45(5):514-519. doi:10.5271/sjweh.3828
\end{abstract}

Objective This paper summarizes the main findings and recommendations of an advisory report on health and prolonging working life, which was requested by the Dutch Minister of Social Affairs and Employment.

Methods The advisory report was compiled by a multidisciplinary committee of ten scientists appointed by the Health Council of The Netherlands. The committee's aims were to (i) describe the health of the ageing population, (ii) describe how prolonging working life influences health, (iii) describe determinants, besides health, for prolonging working lives, and (iv) review the literature on interventions aimed at retaining or improving employability of older workers.

Results The report was presented to the Minister on 26 June 2018. As the likelihood of health problems increases with age, prolonging working life may be difficult. In general, life expectancy increases and gains in life years and health seem mainly attributable to people aged $>75$ years. Work is good for mental health. However, it may be beneficial for mental health to stop working around the retirement age. Besides health, financial factors, lifestyle, motivation to work, and working conditions play a role in prolonging working life. A systematic review of the evidence indicated that interventions such as worksite health promotion or career development workshops can support older workers in this matter.

Conclusions The Health Council advised the Dutch Government to focus on worksite health promotion and career development interventions as well as the improvement of their implementation. This requires a tailored approach as there is a large diversity in health among older workers and particularly between low- and higheducated people. With this in mind, it was further recommended to explore whether flexible pension schemes might better suit this diversity.

Key terms chronic disease; disability benefit; functioning; mental health; need for recovery; older worker; retirement; self-perceived health; sickness absence; unemployment; work ability.

1 The Health Council of The Netherlands, The Hague, The Netherlands.

2 University of Groningen, Department of Health Sciences, University Medical Center Groningen, Groningen, The Netherlands.

3 Department of Public Health, Erasmus MC University Medical Center, Rotterdam, The Netherlands.

4 Amsterdam UMC, VU University Amsterdam, Amsterdam Public Health research institute, Department of Epidemiology and Biostatistics, Amsterdam, The Netherlands.

5 Netherlands Organisation for Applied Scientific Research TNO, Leiden, The Netherlands.

6 Netherlands Interdisciplinary Demographic Institute (NIDI), The Hague, The Netherlands.

7 Department of Health Sciences, University Medical Center Groningen, Groningen, The Netherlands.

8 Department of Sociology, University of Amsterdam, Amsterdam, The Netherlands.

9 Department of Epidemiology, CAPHRI School for Public Health and Primary Care, Faculty of Health, Medicine and Life Sciences, Maastricht University, Maastricht, The Netherlands.

10 Department of Human Resource Management, HAN University of Applied Sciences, Arnhem, Nijmegen, The Netherlands.

11 Faculty of Psychology and Educational Sciences, Open University of the Netherlands, Heerlen, The Netherlands.

12 Department of Economics and Development Economics, VU University Amsterdam, Amsterdam, The Netherlands.

13 Center for Leadership and Management Development, Business University Nyenrode, Breukelen, The Netherlands.

14 Arbo Unie, Utrecht, The Netherlands.

15 Amsterdam UMC, VU University Amsterdam, Amsterdam Public Health research institute, Department of Public and Occupational Health, Amsterdam, The Netherlands.

Correspondence to: Kerstin G van der Mark-Reeuwijk, Health Council of the Netherlands, PO Box. 16052, NL-2500 BB The Hague, The Netherlands. [E-mail: kvandermark@gr.nl] 
Because populations live longer, policies in Western countries are increasingly aimed at prolonging working lives in order to keep the social security system affordable. For example, in The Netherlands, financially attractive early retirement options have been discontinued and access to other exit routes, such as work disability, have been restricted. Furthermore, the official retirement age is being increased in The Netherlands, just as in many other countries $(1,2)$. The Dutch Minister of Social Affairs and Employment asked the Health Council of the Netherlands for advice from a health perspective on prolonging working lives (3).

In general, the likelihood of health problems increases with age. This applies not only to illness, but also to poor self-perceived health, physical limitations, and decreased cognitive functioning $(4,5)$. In addition, older people are more likely to have multiple health problems at the same time. However, there is great diversity within this group when it comes to health (6).

Many factors play a role in prolonging working lives, for example the ability, motivation and opportunity to work (7-9). However, considering the Minister's question, the main focus of the advisory report is on the 'ability' to work, ie, the role of health. Poor health decreases the employability of workers (10-13). For part of the 55-65-year-old workers who exit paid employment before the statutory retirement age (SRA), health plays an important role (14). It mainly concerns people who exit paid employment via work disability, but may also involve people who exit the labor force via unemployment or retirement before their SRA.

The aims of the full advisory report were to (i) describe the health of the ageing population, (ii) describe how prolonging working life influences health, (iii) describe determinants - besides health - for prolonging working lives, and (iv) review the literature on interventions aimed at retaining or improving employability of older workers. This opinion paper summarizes the main findings and recommendations of the full advisory report (available in Dutch) that was submitted to the Dutch Minister of Social Affairs and Employment on 26 June 2018.

\section{The committee and its methodology}

In 2016, the Health Council appointed a committee of ten scientists to address the Minister's questions. The committee members represented multiple disciplines, eg, occupational epidemiology, economics, sociology, human resource management, and occupational medicine. All committee members completed a declaration regarding conflict of interest, which was published on the website of the Health Council (www.gezondheidsraad.nl).
Because the extension of the statutory retirement age has only recently been implemented in The Netherlands and other countries, there is virtually no research on extending working lives (ie, working in a paid job beyond the age of 65 years, the statutory retirement age in the recent past). For that reason, four indicators of decreased employability were used as proxies in this paper: (i) increased need for recovery, (ii) decreased work ability, (iii) increased sickness absence, and (iv) exit from paid employment.

Different data sources and methods were used to answer the questions, ranging from descriptive data and key publications selected by the committee to systematic literature searches in PubMed. To formulate conclusions, the committee also used expert interpretation of the research findings.

\section{Main findings and recommendations}

Based on descriptive data, the committee concluded that currently in The Netherlands, people aged 45-75 years appeared not to be much healthier than people in the same age range two decades ago. Life expectancy at age 65 years has increased, mainly attributable to gained life years between 75 and 84 years of age for men and after 85 years of age for women (15, 16). Healthy life expectancy at age 65 years has also increased. However, this increase was mainly attributable to age-groups $>75$ years. Despite the positive developments in predicted life expectancy at age 65 years, healthy life expectancy at age 65 years, and health at older ages $(17,18)$, the committee expected that these future gains will mainly be attributable to people $>75$ years of age and will not be pertinent to the age range for which retirement age will be raised. However, low-educated older people generally have more health problems and a lower life expectancy and healthy life expectancy than those with a higher educational level $(19,20)$.

\section{And how does this influence work?}

The committee evaluated population attributable fractions (PAF) to estimate the relative importance of health in exit from paid employment. Based on these PAF, it was estimated that poor health played an important role in $16-27 \%$ of Dutch people aged 55-65 years who stopped working due to unemployment $(14,21,22)$. Workers who become unemployed at an older age also have a much smaller chance of finding a new job, especially when they have health problems (9). 


\section{Prolonging working life in relation to health}

Health not only has an effect on whether or not a person is able to prolong working life, but prolonging working life can also have an effect on a person's health (23-25). Working was found to be good for mental health during working age (23). Around the age of retirement, however, it appeared to be more beneficial for mental health to stop working, according to prospective cohort studies $(24,25)$. Findings from natural experiments showed a possible decline in cognitive functioning after retirement, suggesting that retirement may not be beneficial for cognitive health $(26,27)$. However, this has to be confirmed, since work characteristics, timing of retirement (early or 'on time'), and education level seemed to influence this association.

\section{Determinants of prolonging working life - other than health}

According to the committee, financial stimulants seem to play a crucial role in prolonging working lives (28-30). Individual factors, such as a healthy lifestyle and the motivation to work $(31,32)$, and organizational factors, such as decent working conditions, supportive personnel policies, and sufficient autonomy at work, were also found to play an important role $(31,33)$. These factors can offer entrees for supportive interventions. Findings suggested that individual and organizational factors that play a role in employability are quite similar for workers with and without chronic diseases (34). However, autonomy at work seems more important for workers with chronic diseases than for those without chronic diseases (34). In addition, it has been found that loweducated people are often exposed to less favorable working conditions (35).

\section{Interventions aimed at employability of older workers}

The committee performed a literature search in PubMed for systematic reviews of randomized controlled trials (RCT) that evaluated interventions to retain or improve the employability of older workers. The included RCT had to meet the following inclusion criteria: (i) describe the effects on at least one of the four outcomes of interest (ie, need for recovery, work ability, sickness absence, or exit from paid work), (ii) describe interventions for the general working population or a working population with mild health problems or with an increased risk of health problems, and (iii) be published in English in a peer-reviewed scientific journal. Studies were excluded if: (i) the intervention was aimed at a population already on sickness absence or not working for other reasons, (ii) the intervention was conducted in a population with a specific disease, (iii) the intervention was conducted in a student population, (iv) only a per-protocol analysis was available, (v) the methodology was unclear, (vi) only the protocol/design of the RCT was described, (vii) the intervention was a pharmacotherapeutic intervention, or (viii) the intervention took place in a clinical setting.

The search for systematic reviews was supplemented with a systematic search for RCT in PubMed published between 2012 [publication date of the oldest included review (31)] and December 2017 (see table 1). For this search, the same inclusion and exclusion criteria applied as described above. RCT carried out in workers aged $\geq 40$ years ("older workers") were included.

The committee identified seven systematic reviews: three on interventions specifically in older workers $(31,36,37)$ and four umbrella reviews (ie, review of reviews) (38-41). There was a large variation in study populations, outcome measures, and research designs within and between the synthesized studies. Three studies within these reviews met the predefined criteria for inclusion and were supplemented with five more recent RCT from the additional systematic literature search. Thus, in total eight RCT were identified on seven supportive interventions aimed at older workers (42-49).

The seven supportive interventions represented a wide range of measures: career development workshops, worksite health promotion (such as yoga, fitness, availability of free fruits), preventive consultations with an occupational physician, web-based health risk assessment, mental coaching by phone, regular exercise, and Tai Chi. Overall the interventions appeared to have small, positive effects on one or more of the four indicators of employability (ie, increased need for recovery, decreased work ability, increased sickness absence, and exit from paid employment of older workers). However, it has not yet been identified which interventions are most effective for which people at what point of their careers or in what working situations.

\section{Table 1. Search strategy}

The following search strategy was used for aim 4:

\section{Outcome}

("need for recovery"[All Fields] OR workability[All Fields] OR "work ability"[All Fields] OR "work functioning"[All Fields] OR "sick leave"[MeSH Terms] OR (sick[All Fields] AND leave[All Fields]) OR "sick leave"[All Fields] OR absenteeism[MeSH Terms] OR absenteeism[All Fields] OR "sickness absence"[All Fields] OR "work participation"[All Fields] OR "work disability"[All Fields] OR "unemployment"[All Fields] OR "early retirement"[All Fields] OR "disability pension"[All Fields] OR "disability benefit"[All Fields]) NOT "return to work"

\section{Study design}

"randomized controlled trial"[pt] OR "controlled clinical trial"[pt] OR randomized[tiab] OR

placebo[tiab] OR "clinical trials as topic"[MeSH:noexp] OR randomly[tiab] OR trial[ti] OR evaluation studies[publication type] OR "intervention studies"[MeSH Terms] OR intervention studies[All Fields] 


\section{Policy recommendations}

The Health Council advised the government to focus on interventions to support workers in prolonging their working life. Thus far, the positive effects of such interventions have been relatively small, but more effective interventions can be developed, combined with improved implementation of these interventions. Increasing autonomy at work is a promising starting point as well as human resource policies aiming at sustainable employability early in people's careers.

Although problems with employability are not solely observed among low-educated older workers, this group of workers requires special attention when it comes to prolonging working lives. This is because low-educated older workers have more health problems, a lower life (and healthy life) expectancy, and they are often exposed to less favorable working conditions, while they start working at a younger age.

The Health Council also recommended exploring whether flexible pension schemes are a better option compared to today's pension scheme when considering the large diversity in health. This diversity exists within the group of older workers in general and between low- and high-educated people in particular. A specific topic to explore would be whether flexible pension schemes could prevent a health-related exit from work via unemployment.

Furthermore, the Health Council advised to monitor the health of the working population in relation to a longer working life as it is still largely unknown what the health effects are of prolonging working life. It was also recommended to monitor the role of socioeconomic health differences in this perspective. Existing differences in health could be enlarged if people with sufficient personal financial means can afford to exit paid employment when health deteriorates, while people without these means cannot.

\section{Concluding remarks}

In conclusion, from a health perspective, prolonging working lives may be difficult for a substantial minority of workers because the likelihood of health problems increases with age. Moreover, there is a large diversity in health at older age. The Health Council advised to focus on interventions to support workers in prolonging their working lives and to explore whether flexible pension schemes could prevent health-related exit from work via unemployment.

\section{Acknowledgements}

The authors gratefully thank Aleid Ringelberg for her suggestions during the advisory process with respect to current policy.

\section{Conflict of interest \& Funding}

UB, AB, DJHD, GAG, CJIMH, IJK, AdL, ML, WvR, AJvdB received compensation for meeting attendance and travelling expenses from the Health Council of The Netherlands.

The Board of the Health Council consciously weighed the interests and decided that $\mathrm{UB}, \mathrm{AB}, \mathrm{DJHD}$, GAG, CJIMH, IJK, AdL, ML, WvR could participate in the committee without restrictions. AJvdB could participate with the restriction that he would withdraw from the discussion if a subject touches on his consultancy work (did not occur during the course of the project).

The authors declare no conflicts of interest.

\section{References}

1. OECD. Ageing and employment policies: Netherlands 2014: working better with age. OECD Publishing; 2014. https://doi.org/10.1787/9789264208155-en

2. OECD. Pensions at a glance 2017: OECD and G20 indicators. Paris: OECD Publishing; 2017. https://doi. org/10.1787/pension_glance-2017-en

3. The Health Council of the Netherlands. Health and working longer [in Dutch: Gezondheid en langer doorwerken]. The Hague; 2018. Report No.: 2018/14.

4. Statistics Netherlands [internet]. Heerlen. Health and Healthcare use [in Dutch: Gezondheid en zorggebruik] [cited 2018 April]. Available from: https://opendata.cbs.nl/statline/\#/ $\mathrm{CBS} / \mathrm{nl} /$ dataset $/ 83005 \mathrm{NED} /$ table?ts $=1517307092589$

5. Broese van Groenou M, Deeg DJ, de Boer A. Changes in the life course. In: de Boer A, editor. Report on the Elderly [in Dutch: Rapportage ouderen 2006]. The Hague: Social and Cultural Planning Office of the Netherlands; 2006. p167-93.

6. Vriend S, Heyma A, van der Noordt M, Deeg DJ. Continuing to work longer with an occupational disability [in Dutch: Langer doorwerken met arbeidsbeperking - prognose van de arbeidsparticipatie van ouderen tot 2030 in relatie tot gezondheidsontwikkelingen]. Amsterdam: SEO Amsterdam Economics; 2016. Report no. 2016-89.

7. van Solinge H, Henkens K. Involuntary retirement: the role of restrictive circumstances, timing, and social embeddedness. J Gerontol B Psychol Sci Soc Sci 2007 Sep;62(5):S295-303. https://doi.org/10.1093/geronb/62.5.S295

8. Oude Mulders J, van Dalen HP, Henkens K, Schippers J. How likely are employers to rehire older workers after 
mandatory retirement? A vignette study among managers. Economist (Leiden) 2014;162(4):415-31. https://doi. org/10.1007/s10645-014-9234-8

9. Schuring M, Robroek SJ, Otten FW, Arts CH, Burdorf A. The effect of ill health and socioeconomic status on labor force exit and re-employment: a prospective study with ten years follow-up in the Netherlands. Scand J Work Environ Health 2013 Mar;39(2):134-43. PubMed https://doi. org/10.5271/sjweh.3321

10. Leijten FR, van den Heuvel SG, Ybema JF, van der Beek AJ, Robroek SJ, Burdorf A. The influence of chronic health problems on work ability and productivity at work: a longitudinal study among older employees. Scand J Work Environ Health 2014 Sep;40(5):473-82. PubMed https:// doi.org/10.5271/sjweh.3444

11. Stansfeld SA, Fuhrer R, Head J. Impact of common mental disorders on sickness absence in an occupational cohort study. Occup Environ Med 2011 Jun;68(6):408-13. PubMed https://doi.org/10.1136/oem.2010.056994

12. Magee CA, Caputi P, Lee JK. Distinct longitudinal patterns of absenteeism and their antecedents in full-time Australian employees. J Occup Health Psychol 2016 Jan;21(1):24-36. PubMed https://doi.org/10.1037/a0039138

13. van Rijn RM, Robroek SJ, Brouwer S, Burdorf A. Influence of poor health on exit from paid employment: a systematic review. Occup Environ Med 2014 Apr;71(4):295-301. PubMed https://doi.org/10.1136/oemed-2013-101591

14. van den Berg T, Schuring M, Avendano M, Mackenbach J, Burdorf A. The impact of ill health on exit from paid employment in Europe among older workers. Occup Environ Med 2010 Dec;67(12):845-52. PubMed https://doi. org/10.1136/oem.2009.051730

15. Deeg DJ, van der Noordt M, Hoogendijk E, Comijs HC, Huisman M. Employability after age 65? Trends over 23 years in life expectency in good and in poor physical and cognitive health of 65-74-year-olds in the Netherlands. 2018. Report No.: Netspar Design Paper 96.

16. Statistics Netherlands [internet]. Heerlen. Healthy life expectancy; from 1981 [in Dutch: Gezonde levensverwachting; vanaf 1981] [cited 2017 July 20]. Available from: https://opendata.cbs.nl/statline/\#/CBS/n1/ dataset/71950ned/table?ts=1517307172937

17. Statistics Netherlands [internet]. Heerlen. Living longer without disabilities [in Dutch: Steeds langer leven zonder beperkingen] [cited 2018 May]. Available from: https:// www.cbs.nl/nl-nl/nieuws/2018/12/steeds-langer-levenzonder-beperkingen

18. National Institute for Public Health and the Environment [internet]. Bilthoven. [in Dutch: Volksgezondheid Toekomst Verkenning 2018] [cited 2018 May]. Available from: https:// www.vtv2018.nl/gezondheid

19. Galenkamp H, Braam AW, Huisman M, Deeg DJ. Seventeen-year time trend in poor self-rated health in older adults: changing contributions of chronic diseases and disability. Eur J Public Health 2013 Jun;23(3):511-7. https:// doi.org/10.1093/eurpub/cks031
20. Statistics Netherlands [internet]. Heerlen. Healthy life expectancy; education level [in Dutch: Gezonde levensverwachting; onderwijsniveau] [cited 2017 May]. Available from: http://statline.cbs.nl/Statweb/publication/? $\mathrm{DM}=\mathrm{SLNL} \& \mathrm{PA}=83780 \mathrm{ned} \& \mathrm{D} 1=0,3 \& \mathrm{D} 2=0 \& \mathrm{D} 3=14 \& \mathrm{D}$ $4=\mathrm{a} \& \mathrm{D} 5=0 \& \mathrm{D} 6=1 \& \mathrm{HDR}=\mathrm{T} \& \mathrm{STB}=\mathrm{G} 1, \mathrm{G} 2, \mathrm{G} 3, \mathrm{G} 4, \mathrm{G} 5 \& \mathrm{~V}$ $\mathrm{W}=\mathrm{T}$

21. Boot CR, Deeg DJ, Abma T, Rijs KJ, van der Pas S, van Tilburg TG et al. Predictors of having paid work in older workers with and without chronic disease: a 3-year prospective cohort study. J Occup Rehabil 2014 Sep;24(3):563-72.

22. Leijten FR, de Wind A, van den Heuvel SG, Ybema JF, van der Beek AJ, Robroek SJ et al. The influence of chronic health problems and work-related factors on loss of paid employment among older workers. J Epidemiol Community Health 2015 Nov;69(11):1058-65. https://doi.org/10.1136/ jech-2015-205719

23. van der Noordt $M$, IJzelenberg H, Droomers $M$, Proper KI. Health effects of employment: a systematic review of prospective studies. Occup Environ Med 2014 Oct;71(10):730-6. https://doi.org/10.1136/ oemed-2013-101891

24. van der Heide I, van Rijn RM, Robroek SJ, Burdorf A, Proper KI. Is retirement good for your health? A systematic review of longitudinal studies. BMC Public Health 2013 Dec;13:1180. https://doi.org/10.1186/1471-2458-13-1180

25. Schaap R, de Wind A, Coenen P, Proper K, Boot C. The effects of exit from work on health across different socioeconomic groups: A systematic literature review. Soc Sci Med 2018 Feb;198:36-45. https://doi.org/10.1016/j. socscimed.2017.12.015

26. Celidoni M, Dal Bianco C, Weber G. Retirement and cognitive decline. A longitudinal analysis using SHARE data. J Health Econ 2017 Dec;56:113-25. https://doi. org/10.1016/j.jhealeco.2017.09.003

27. Bonsang E, Adam S, Perelman S. Does retirement affect cognitive functioning? J Health Econ 2012 May;31(3):490 501. https://doi.org/10.1016/j.jhealeco.2012.03.005

28. Gruber J, Wise D. Social security and retirement: an international comparison. Am Econ Rev 1998;88(2):158 63.

29. Statistics Netherlands [internet]. Heerlen. From work to retirement; people of 55 years and older [in Dutch: Van arbeid naar pensioen; personen 55 jaar of ouder] [cited 2017 November]. Available from: https:// opendata.cbs.nl/statline/\#/CBS/nl/dataset/80396ned/ table?ts $=1511513817398$

30. Bratberg E, Holmås TH, Thøgersen $\varnothing$. Assessing the effects of an early retirement program. J Popul Econ 2004;17(3):387-408. https://doi.org/10.1007/s00148-0030165-y

31. Brouwer S, de Lange A, van der Mei S, Wessels M, Koolhaas W, Bültmann U et al. Sustainable employability of older workers: state of knowledge [in Dutch: Duurzame inzetbaarheid van oudere werknemers: stand van 
zaken: overzicht van determinanten, interventies en meetinstrumenten vanuit verschillende perspectieven]. Groningen: University Medical Center Groningen; 2012.

32. Robroek SJ, Reeuwijk KG, Hillier FC, Bambra CL, van Rijn RM, Burdorf A. The contribution of overweight, obesity, and lack of physical activity to exit from paid employment: a meta-analysis. Scand J Work Environ Health 2013 May;39(3):233-40. https://doi.org/10.5271/sjweh.3354

33. Pak K, Kooij DT, De Lange AH, Van Veldhoven MJ. Human Resource Management and the ability, motivation and opportunity to continue working: A review of quantitative studies. Hum Resour Manage R. 2018. https://doi. org/10.1016/j.hrmr.2018.07.002

34. Sewdas R, van der Beek AJ, de Wind A, van der Zwaan LGL, Boot CRL. Determinants of working until retirement compared to a transition to early retirement among older workers with and without chronic diseases: results from a Dutch prospective cohort study. Scand J Public Health. 2017 https://doi.org/10.1177/1403494817735223

35. Robroek SJ, Rongen A, Arts CH, Otten FW, Burdorf A, Schuring M. Educational inequalities in exit from paid employment among Dutch workers: the influence of health, lifestyle and work. PLoS One 2015 Aug;10(8):e0134867. https://doi.org/10.1371/journal.pone.0134867

36. Cloostermans L, Bekkers MB, Uiters E, Proper KI. The effectiveness of interventions for ageing workers on (early) retirement, work ability and productivity: a systematic review. Int Arch Occup Environ Health 2015 Jul;88(5):52132. https://doi.org/10.1007/s00420-014-0969-y

37. Poscia A, Moscato U, La Milia DI, Milovanovic S, Stojanovic J, Borghini A et al. Workplace health promotion for older workers: a systematic literature review. BMC Health Serv Res 2016 Sep;16 Suppl 5:329. https://doi. org/10.1186/s12913-016-1518-z

38. Wagner SL, White MI, Schultz IZ, Williams-Whitt K, Koehn $\mathrm{C}$, Dionne CE et al. Social support and supervisory quality interventions in the workplace: a stakeholder-centered bestevidence synthesis of systematic reviews on work outcomes. Int J Occup Environ Med 2015 Oct;6(4):189-204. https:// doi.org/10.15171/ijoem.2015.608

39. Williams-Whitt K, White MI, Wagner SL, Schultz IZ, Koehn C, Dionne CE et al. Job demand and control interventions: a stakeholder-centered best-evidence synthesis of systematic reviews on workplace disability. Int J Occup Environ Med 2015 Apr;6(2):61-78. https://doi. org/10.15171/ijoem.2015.553

40. Wagner SL, Koehn C, White MI, Harder HG, Schultz IZ, Williams-Whitt $\mathrm{K}$ et al. Mental health interventions in the workplace and work outcomes: a best-evidence synthesis of systematic reviews. Int J Occup Environ Med 2016 Jan;7(1):1-14. https://doi.org/10.15171/ijoem.2016.607
41. White MI, Dionne CE, Wärje O, Koehoorn M, Wagner SL, Schultz IZ et al. Physical activity and exercise interventions in the workplace impacting work outcomes: a stakeholdercentered best evidence synthesis of systematic reviews. Int $\mathrm{J}$ Occup Environ Med 2016 Apr;7(2):61-74. PubMed https:// doi.org/10.15171/ijoem.2016.739

42. Toppinen-Tanner S, Böckerman P, Mutanen P, Martimo KP, Vuori J. Preventing sickness absence with career management intervention: a randomized controlled field trial. J Occup Environ Med 2016 Dec;58(12):1202-6. https://doi.org/10.1097/JOM.0000000000000887

43. Strijk JE, Proper KI, van der Beek AJ, van Mechelen W. A worksite vitality intervention to improve older workers' lifestyle and vitality-related outcomes: results of a randomised controlled trial. J Epidemiol Community Health 2012 Nov;66(11):1071-8. https://doi.org/10.1136/ jech-2011-200626

44. Strijk JE, Proper KI, van Mechelen W, van der Beek AJ. Effectiveness of a worksite lifestyle intervention on vitality, work engagement, productivity, and sick leave: results of a randomized controlled trial. Scand J Work Environ Health 2013 Jan;39(1):66-75. https://doi.org/10.5271/sjweh.3311

45. de Boer AG, van Beek JC, Durinck J, Verbeek JH, van Dijk FJ. An occupational health intervention programme for workers at risk for early retirement; a randomised controlled trial. Occup Environ Med 2004 Nov;61(11):924-9. https:// doi.org/10.1136/oem.2003.009746

46. Adler DA, Lerner D, Visco ZL, Greenhill A, Chang H, Cymerman E et al. Improving work outcomes of dysthymia (persistent depressive disorder) in an employed population. Gen Hosp Psychiatry 2015 Jul-Aug;37(4):352-9. https:// doi.org/10.1016/j.genhosppsych.2015.04.001

47. Rutanen R, Nygård CH, Moilanen J, Mikkola T, Raitanen J, Tomas E et al. Effect of physical exercise on work ability and daily strain in symptomatic menopausal women: a randomized controlled trial. Work 2014;47(2):281-6.

48. Palumbo MV, Wu G, Shaner-McRae H, Rambur B, McIntosh B. Tai Chi for older nurses: a workplace wellness pilot study. Appl Nurs Res 2012 Feb;25(1):54-9. https://doi. org/10.1016/j.apnr.2010.01.002

49. Kouwenhoven-Pasmooij TA, Robroek SJ, Kraaijenhagen RA, Helmhout PH, Nieboer D, Burdorf A et al. Effectiveness of the blended-care lifestyle intervention 'PerfectFit': a cluster randomised trial in employees at risk for cardiovascular diseases. BMC Public Health 2018 Jun;18(1):766. https://doi.org/10.1186/s12889-018-5633-0

Received for publication: 25 January 2019 